\title{
Study and Implementation of Autonomous Water Desalination Unit Driven by Solar Energy
}

\author{
Fahad Albukhari \\ University of Bridgeport, Electrical Engineering, USA
}

\begin{abstract}
In this paper autonomous water desalination unit driven by solar energy was discussed in details. Photovoltaic method by using semiconductors. The algorithm changes the duty cycle of the dc/dc converter to maximum the power output of the module and make it operate at the peak power point of the module. a class of switching-mode power supply (SMPS) containing at least two semiconductor switches and at least one energy storage element.
\end{abstract}

Keywords: Water, Desalination, Solar, Photovoltaic, Algorithm.

\section{INTRODUCTION}

Water resources are essential for satisfying human needs, protecting health, and ensuring food production, energy and the restoration of ecosystems, as well as for social and economic development and for sustainable development [1].However, according to UN World Water Development Report in 2003, it has been estimated that two billion people are affected by water shortages in over forty countries, and 1.1 billion do not have sufficient drinking water. The use of renewable energy for water treatment systems is a very attractive proposition. photovoltaic are able to produce electricity only when the sunlight is available, therefore stand-alone systems obviously need some sort of backup energy storage which makes them available through the night or bad weather conditions. The lead-acid battery continues to be the workhorse of many PV systems because it is relatively inexpensive and widely available. In addition to energy storage, the battery also has ability to provide surges of current that are much higher than the instantaneous current available from the array, as well as the inherent and automatic property controlling the output voltage of the array so that loads receive voltages within their own range of acceptability [2]. The type of lead-acid battery suitable for PV systems is a deep-cycle battery which is different from one used for automobiles, and it is more expensive and not widely available. Battery lifetime in PV systems is typically three to eight years, but this reduces to typically two to six years in hot climate since high ambient temperature dramatically increases the rate of internal corrosion. Experienced PV system designers avoid batteries whenever possible [3].

\section{DESALINATION SYSTEM DESCRIPTION}

The desalination system is composed of a photovoltaic array, Accumulator batteries, and The RO desalination unit. The PV generator consists of an array of photovoltaic cell modules connected in series-parallel combination to provide the desired DC voltage and current. The adaptor converts the continuous voltage delivered by the battery to an alternative voltage in order to feed the motor pump group which provides pressurized water to the membrane. The desalination unit is composed by three RO modules, each one of them is composed by a membrane which is constituted of a thin film composite modified polyamide type able to purify feed water containing up to $3,000 \mathrm{ppm}$ of total dissolved solids. These modules have a nominal capacity $1500 \mathrm{~L} / \mathrm{d}$ at $800 \mathrm{k} \mathrm{Pa}$ figure 1.

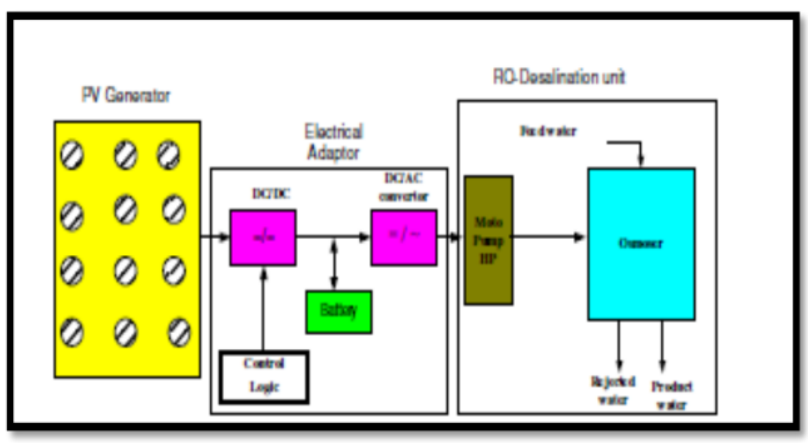

Fig.1 Desalination system Coupled to Photovoltaic Generator

\section{PHOTOVOLTAIC METHOD}

Photovoltaics (PV) is a method of generating electrical power by converting solar radiation into direct current electricity using semiconductors that exhibit the photovoltaic effect [4]. The photovoltaic effect is the creation of a voltage (or a corresponding electric current) in a material upon exposure to light. Though the photovoltaic effect is directly related to the photoelectric effect, the two processes are different and should be distinguished. In the photoelectric effect, electrons are ejected from a material's surface upon exposure to radiation of sufficient energy. Solar cells produce direct current electricity from sun light, which can be used to power equipment or to recharge a battery. an inverter is required to convert the $\mathrm{DC}$ to $\mathrm{AC}$. When solar panels are normally mounted at an angle, will receive more energy per unit area figure 2.

There are several types of semiconductor technologies currently in use for PV solar panels. Two, however, have become the most widely adopted: crystalline silicon and thin film [6]. A photovoltaic array is a linked collection of photovoltaic modules, which are in turn made of multiple interconnected solar cells figure 3 . 


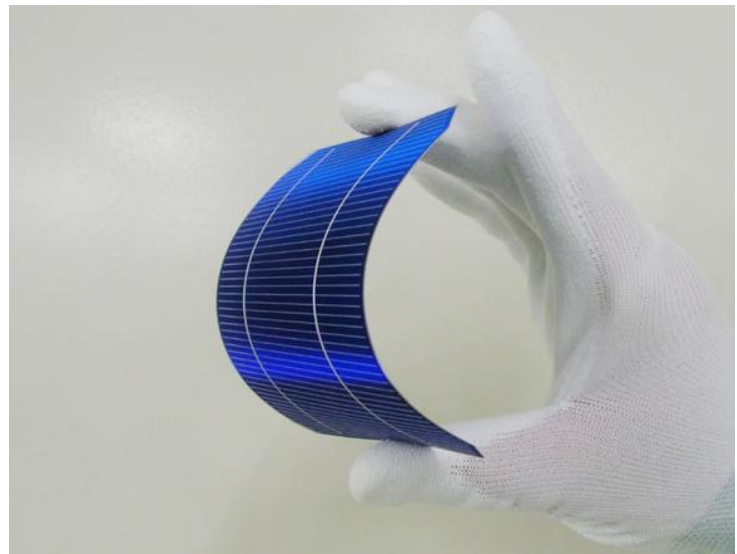

Fig.2 Solar Panels

By their modularity, they are able to be configured to supply most loads. The power that one module can produce is seldom enough to meet requirements of a home or a business, so the modules are linked together to form an array.

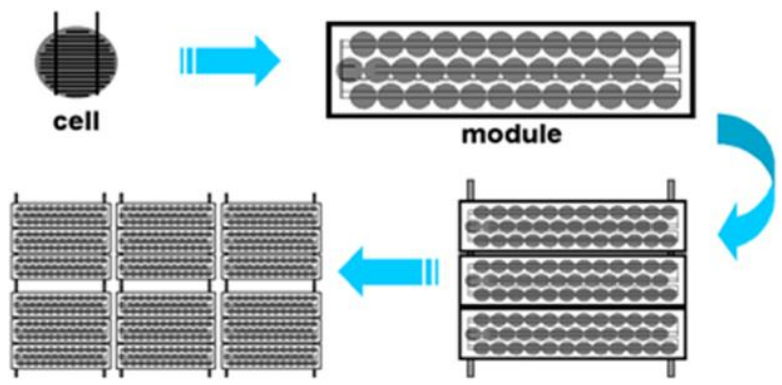

Fig.3Photovoltaic Array

\section{MAXIMUM PEAK POWER TRACKING}

The peak power is reached with the help of a dc/dc converter by adjusting its duty cycle such that resistance corresponding to the peak power is obtained. Now question arises how to vary the duty cycle and in which direction so that peak power is reached. Whether manual tracking or automatic tracking? Manual tracking is not possible so automatic tracking is preferred to manual tracking. The algorithms are implementing in microcontroller or a personal computer to implement maximum power tracking. The algorithm changes the duty cycle of the dc/dc converter to maximum the power output of the module and make it operate at the peak power point of the module.

The voltage based peak tracking is assumed maximum power point of a particular solar PV module lies at about 0.75 times the open circuit voltage of the module. So by measuring the open circuit voltage a reference voltage can be generated and feed forward voltage control scheme can be implemented to bring the solar PV module voltage to the point of maximum power. The current based peak power tracking is the peak power of the module lies at the point which is about 0.9 times short circuit current of the module. In order to measure this point, the module or array is short -circuit Ed [9].

The disadvantage of the perturb and observe method to track the peak power under fast varying atmospheric condition is overcome by Incremental conductance method. In order to keep the power variation small, the perturbation size is kept very small. The algorithm is developed in such a manner that it sets a reference voltage of the module corresponding to the peak voltage of the module figure 4. A PI controller then acts moving the operating point of the module to that particular voltage level. It is observed that there some power loss due to this perturbation also the fails to track the power under fast varying atmospheric conditions. But still this algorithm is very popular and simple.

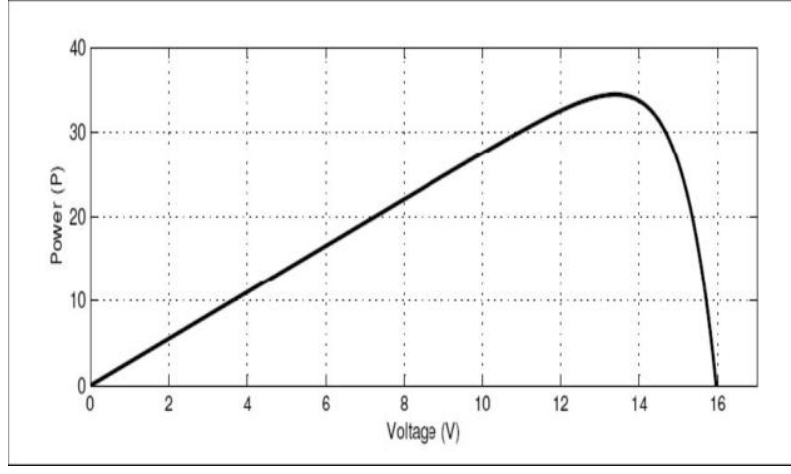

Fig.4Perturb and Observe

\section{BOOST CHOPPER}

A class of switching-mode power supply (SMPS) containing at least two semiconductor switches (a diode and a transistor) and at least one energy storage element. Filters made of capacitors (sometimes in combination with inductors) are normally added to the output of the converter to reduce output voltage ripple. Power can also come from DC sources such as batteries, solar panels, rectifiers and DC generators. A process that changes one DC voltage to a different DC voltage is called DC to DC conversion. A boost converter is a DC to DC converter with an output voltage greater than the source voltage. A boost converter is sometimes called a step-up converter since it "steps up" the source voltage. Since power $(\mathrm{P}=$ VI) must be conserved, the output current is lower than the source current [6]. A boost converter is used as the voltage increase mechanism in the circuit known as the 'Joule thief'. This circuit topology is used with low power battery applications, and is aimed at the ability of a boost converter to 'steal' the remaining energy in a battery. This energy would otherwise be wasted since the low voltage of a nearly depleted battery makes it unusable for a normal load. The key principle that drives the boost converter is the tendency of an inductor to resist changes in current. When being charged it acts as a load and absorbs energy (somewhat like a resistor), when being discharged, it acts as an energy source [5].

The key principle that drives the boost converter is the tendency of an inductor to resist changes in current. When being charged it acts as a load and absorbs energy (somewhat like a resistor), when being discharged, it acts as an energy source [8]. The voltage it produces during the discharge phase is related to the rate of change of current, and not to the original charging voltage, thus allowing different input and output voltages 
When a boost converter operates in continuous mode, the current through the inductor (IL) never falls to zero. The typical waveforms of currents and voltages in a converter operating in this mode. The output voltage can be calculated as follows, in the case of an ideal converter operating in steady conditions figure 5 .

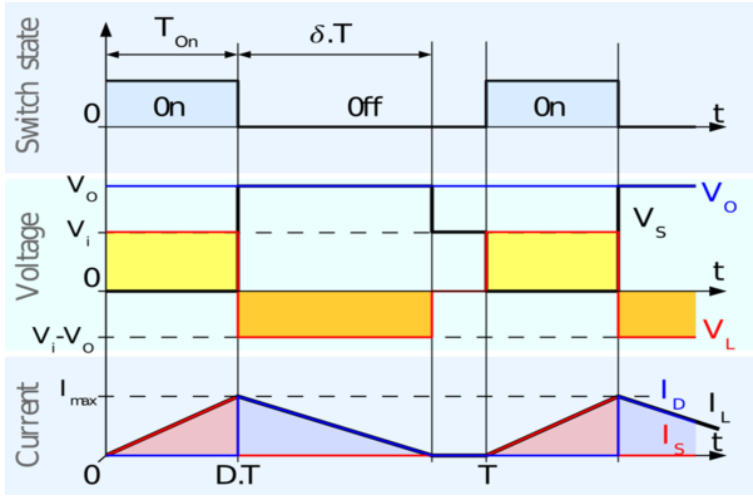

Fig.5Wave Forms

During the On-state, the switch $\mathrm{S}$ is closed, which makes the input voltage (Vi) appear across the inductor, which causes a change in current (IL) flowing through the inductor during a time period $(\mathrm{t})$.

$$
\frac{\Delta I_{L}}{\Delta t}=\frac{V_{i}}{L}
$$

\section{SIMULATION RESULTS}

The effect of Isc on PV voltage and current has been studded and evaluated. Also, effect of isc on pv voltage and power is analyzed. Figure 6 shows how the I-V characteristic changes depending on irradiation $G$ (in $\mathrm{kW} / \mathrm{m} 2$ ) when $\mathrm{Ta}=25^{\circ} \mathrm{C}$, given that $\mathrm{np}=1.5$, Since ISC is directly proportional to $\mathrm{G}$, the characteristic curves in graph shows the predicted response to the change of irradiation. There is a change in VOC as G reduces.

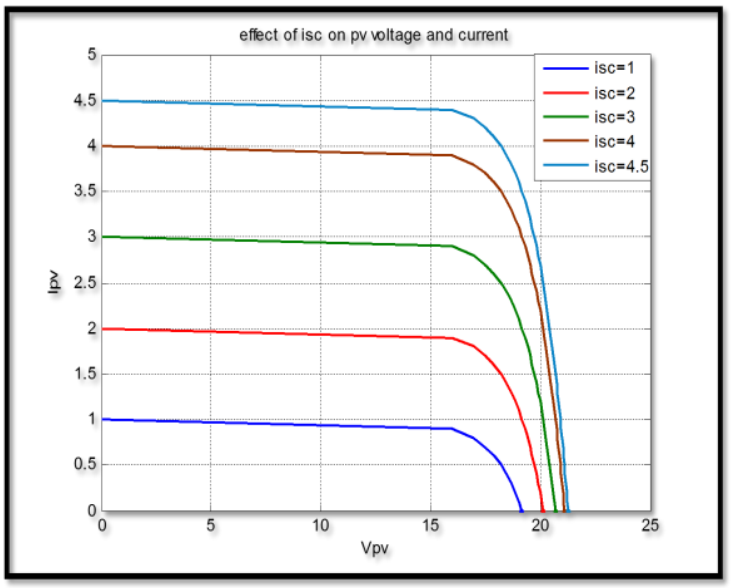

Fig.6 Effect of Isc on PV Voltage and Current

Figure 7shows the P-V characteristic curves for the PV module, and their dependence on irradiation $G$ (in $\mathrm{kW} / \mathrm{m} 2$ ). The curves show the expected results, which correspond to the $\mathrm{I}-\mathrm{V}$ characteristics. With reduction of $\mathrm{G}$, power decreases due to decrease in current and increase of $\mathrm{T}$ reduces power due to decrease in $\mathrm{V}$.

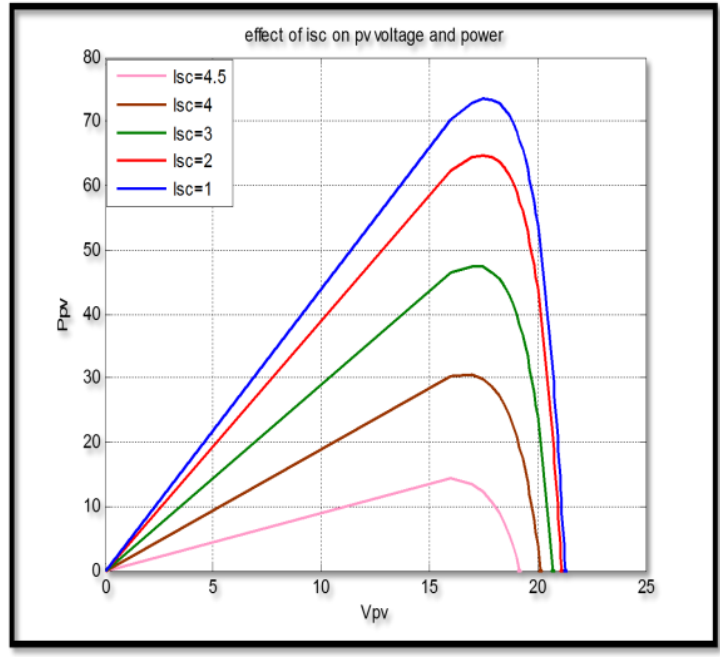

Fig.7 Effect of Isc on PV Voltage and Power

\section{CONCLUSION}

The proposal method can be used to water desalination in some areas that do not have AC powered. Also, it has a great opportunity of green energy. The consumption of fossil fuels also has an environmental impact. photovoltaic are able to produce electricity only when the sunlight is available, therefore stand-alone systems obviously need some sort of backup energy storage which makes them available through the night or bad weather conditions. The type of lead-acid battery suitable for PV systems is a deepcycle battery which is different from one used for automobiles, and it is more expensive and not widely available. Battery lifetime in PV systems is typically three to eight years, but this reduces to typically two to six years in hot climate since high ambient temperature dramatically increases the rate of internal corrosion. Batteries also require regular maintenance and will degrade very rapidly if the electrolyte is not topped up and the charge is not maintained.

\section{REFRENCES}

[1] Banat, F., \& Jwaied, N. (2008). Economic evaluation of desalination by small-scale autonomous solar-powered membrane distillation units. Desalination, 220(1), 566-573.

[2] Crebier, J. C., Revol, B., \& Ferrieux, J. P. (2005). Boost-chopperderived PFC rectifiers: interest and reality. Industrial Electronics, IEEE Transactions on, 52(1), 36-45.

[3] Erbs, D. G., Klein, S. A., \& Duffie, J. A. (1982). Estimation of the diffuse radiation fraction for hourly, daily and monthly-average global radiation. Solar energy, 28(4), 293-302.

[4] Garcia-Rodriguez, L. (2002). Seawater desalination driven by renewable energies: a review. Desalination, 143(2), 103-113.

[5] Green, M. A. (1982). Solar cells: operating principles, technology, and system applications.

[6] Hua, C., \& Shen, C. (1998, February). Comparative study of peak power tracking techniques for solar storage system. In Applied Power Electronics Conference and Exposition, 1998. APEC'98. Conference Proceedings 1998. Thirteenth Annual (Vol. 2, pp. 679-685). IEEE.

[7] Keevers, M. J., \& Green, M. A. (1994). Efficiency improvements of silicon solar cells by the impurity photovoltaic effect. Journal of Applied Physics, 75(8), 4022-4031.

[8] Salas, V., Olias, E., Barrado, A., \& Lazaro, A. (2006). Review of the maximum power point tracking algorithms for stand-alone photovoltaic systems. Solar energy materials and solar cells, 90(11), 1555-1578.

[9] Tzen, E., Perrakis, K., \& Baltas, P. (1998). Design of a stand alone PVdesalination system for rural areas. Desalination, 119(1), 327-333. 